\title{
The attitudes of Korean medical students toward patient safety
}

\author{
Kwi Hwa Park', Kyung Hye Park ${ }^{2,3}$, Youngjoon Kang ${ }^{4}$ and Oh Young Kwon ${ }^{5}$ \\ ${ }^{1}$ Department of Medical Education, Gachon University College of Medicine, Incheon, ${ }^{2}$ Department of Medical \\ Education, Yonsei University Wonju College of Medicine, ${ }^{3}$ Department of Emergency Medicine, Wonju Severance \\ Christian Hospital, Wonju, ${ }^{4}$ Department of Medical Education, Jeju National University School of Medicine, \\ Jeju, and ${ }^{5}$ Department of Medical Education and Medical Humanities, Kyung Hee University School of Medicine, \\ Seoul, Korea
}

Purpose: This study investigated the attitudes of Korean medical students about patient safety to determine which perspectives required increased focus in terms of educational development.

Methods: Attitudes were assessed using the Patient Safety Questionnaire, a tool designed to measure attitudes toward patient safety among medical students. Questionnaires were distributed to 580 clinical year students across four medical schools in December 2018.

Results: A total of 300 returned questionnaires were used in the final analysis. More than half of all respondents agreed (i.e., gave more than 4 out of 7 points) with most items and thoroughly considered the concept of patient safety. However, many students misperceived several items (e.g., professional incompetence as a cause of errors, disclosure responsibility, the importance of patient safety in the curriculum, and situational awareness).

Conclusion: Attitudes toward patient safety are highly important due to their substantial impacts on behavioral decisions in the clinical setting. As such, patient safety education should be designed to place greater emphasis on proper attitude. This study's findings should be useful for medical instructors who wish to determine the appropriate areas of curricular focus.

Key Words: Medical students, Patient safety, Medical education, Attitude, Surveys and questionnaires

\section{Introduction}

The hospital safety report titled "To err is human" was published in 1999 [1]. Since then, increased attention has been paid to patient safety. For instance, there has been growing concern that various adverse events and medical errors can be prevented by increasingly engaging in patient-safety activities. As such, many hospitals strive to improve patient safety and quality through an accreditation evaluation system. There is also an increased need for both health care workers and medical students to directly learn about patient safety.

However, the idea of patient safety is still underdeveloped in the context of undergraduate medical education, especially true in Korea. One Korean study found that $73.7 \%$ of all respondents positively assessed the importance of medical error disclosure, but that less
Received: August 19, 2019 • Revised: October 10, 2019 • Accepted: October 21, 2019 Corresponding Author: Kyung Hye Park (https://orcid.org/0000-0002-5901-6088)

Department of Medical Education, Yonsei University Wonju College of Medicine, 20 Ilsan-ro, Wonju 26426, Korea

Tel: +82.33.741.0242 Fax:+82.33.742.5034 email: erdoc74@gmail.com
Korean J Med Educ 2019 Dec; 31(4): 363-369.

https://doi.org/10.3946/kjme.2019.146

eISSN: 2005-7288

(C) The Korean Society of Medical Education. All rights reserved. This is an open-access article distributed under the terms of the Creative Commons Attribution Non-Commercial License (http:// creativecommons.org/licenses/by-nc/3.0/), which permits unrestricted non-commercial use, distribution, and reproduction in any medium, provided the original work is properly cited. 
than $20 \%$ had received education or training on how to disclose errors and thus had negative perceptions of the error disclosure culture [2].

The World Health Organization World Alliance for Patient Safety released its Patient Safety Curriculum for Medical Schools in 1999 [3]. In 2017, the Korea Association of Medical Colleges published eight learning outcomes related to human and society-centered issues such as patient safety [4]. As such, it is expected that patient-safety education programs will gradually increase in popularity. Before developing a patient safety curriculum, it is thus necessary to determine the related perceptions and attitudes of medical students. These perceptions should be thoroughly considered when developing educational contents. This study therefore aimed to identify baseline patient safety attitudes and educational needs using one validated survey instrument developed for use with medical students.

\section{Methods}

\section{Attitude to patient safety questionnaire}

The attitude to patient safety questionnaire (APSQ) was developed to measure attitudes about patient safety among medical students (reliability coefficients from 0.64 to 0.82 ) [5]. Responses to each item were rated on a Likert scale ranging from 1 (strongly disagree) to 7 (strongly agree). Several items were reverse scored. Higher scores indicated more affirmative (or positive) responses to the concerned factors. The APSQ was translated into Korean according to established guidelines after obtaining permission from the corresponding author listed in the original study [5,6] (Fig. 1). This

\section{Fig. 1. Process of Translating the Attitude to Patient Safety Questionnaire from English into Korean}

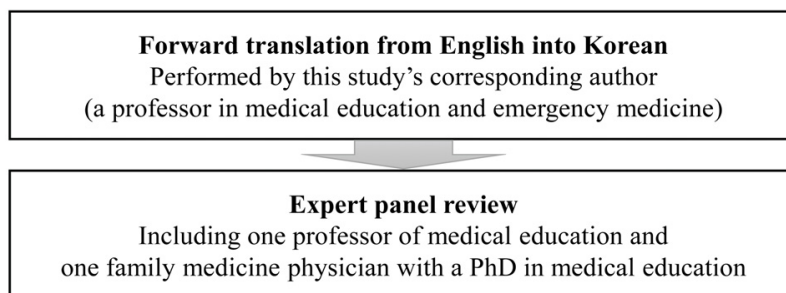

Back translation from Korean into English

Performed by one bilingual emergency physician

Pretesting and cognitive interviewing

Performed among nine third or fourth-year medical students

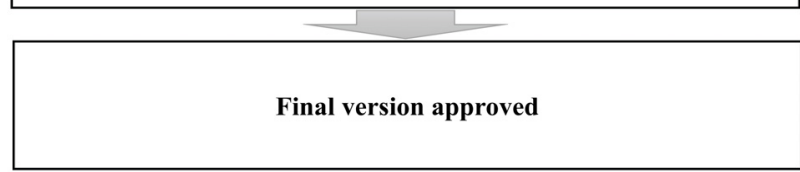

Table 1. Characteristics of the Four Participating Institutions

\begin{tabular}{|c|c|c|c|}
\hline Institution & Entry system & Medical humanity courses & $\begin{array}{l}\text { Total no. of 3rd and } \\
4 \text { th year students }\end{array}$ \\
\hline A & High school entry & $\begin{array}{l}\text { Six "patient-doctor-society" courses, including behavioral and social sciences, ethics, } \\
\text { and law } \\
\text { A "transition course for clinical clerkship," including communication }\end{array}$ & 200 \\
\hline B & Graduate entry ${ }^{\mathrm{b}}$ & $\begin{array}{l}\text { Eight "patient-doctor-society" courses, including behavioral and social sciences, } \\
\text { ethics, law, and communication }\end{array}$ & 80 \\
\hline C & Graduate entry ${ }^{\mathrm{bl}}$ & $\begin{array}{l}\text { Four "patient-doctor-society" courses, including managing, ethics, law, and } \\
\text { communication }\end{array}$ & 220 \\
\hline D & Graduate entry ${ }^{\text {bl }}$ & $\begin{array}{l}\text { Five "patient-doctor-society" courses, including behavioral and social sciences, } \\
\text { ethics, law, and communication }\end{array}$ & 80 \\
\hline
\end{tabular}

\footnotetext{
${ }^{\text {a) }}$ An undergraduate program consisting of a 2-year pre-medical course, 2-year medical course, and 2-year clinical clerkship. Medical students can enter medical school after finishing high school. ${ }^{b}$ Post-baccalaureate program consisting of a 2-year medical course and 2-year clinical clerkship. Medical students can enter medical school after finishing a 4-year college degree.
} 
study specifically used the APSQ version 4 (the most current) based on a recommendation from Lawton, the same individual.

\section{Survey}

This study was approved by the Institutional Review Board of Yonsei University Wonju Severance Christian Hospital (CR318102). A cross-sectional, self-administered questionnaire survey was anonymously conducted among 580 third- and fourth-year medical students from four total institutions in Korea during December 2018. Each had completed more than 1 year of their clinical clerkship and had received no prior formal instruction on patient safety (Table 1). Questionnaires were distributed to all participants using an internet survey service (https://ko.surveymonkey.com).

\section{Statistical analyses}

Attitude scores were presented as mean and standard variations or the numbers and ratio of agreement. Data were analyzed using IBM SPSS ver. 23.0 (IBM Corp., Armonk, USA).

\section{Results}

A total of 343 medical students responded to the survey (response rate of 59.1\%). After excluding those with incomplete responses, 300 were used for analysis (180 third year students [60.0\%], 175 males [58.3\%]; mean age, $26.90 \pm 2.38$ years). The survey received a Cronbach's $\alpha$ of 0.720 .

For general patient safety, over one-third of all respondents thought that most harm to patients was unavoidable. Over $60 \%$ were satisfied with and positively rated the patient-safety training they had received up until the time of survey. Most thought that it was important for undergraduate medical students to receive formal instruction on patient safety. However, $41 \%$ believed that patient safety could instead be learned

Table 2. Medical Students' Attitude toward Patient Safety

\begin{tabular}{|c|c|c|c|}
\hline Domain & Item & $\begin{array}{c}\text { No. of } \\
\text { agreements }(\%)\end{array}$ & $\begin{array}{l}\text { Mean } \pm \text { standard } \\
\text { deviation }\end{array}$ \\
\hline \multirow[t]{2}{*}{$\begin{array}{l}\text { Patient safety: } \\
\text { general }\end{array}$} & $\begin{array}{l}\text { When things go wrong, learning from error is more important than disciplining } \\
\text { individuals. }\end{array}$ & $255(85.0)$ & $5.71 \pm 1.27$ \\
\hline & Most harm to patients is unavoidable. $<\mathrm{R}>$ & 109 (36.3) & $3.91 \pm 1.63$ \\
\hline \multirow{3}{*}{$\begin{array}{l}\text { Patient safety } \\
\text { training received } \\
\text { to date }\end{array}$} & My training is preparing me to understand the cause of errors. & $185(61.7)$ & $4.83 \pm 1.47$ \\
\hline & I have a good understanding of patient safety as a result of my training. & $195(65.0)$ & $5.00 \pm 1.43$ \\
\hline & My training is preparing me to prevent medical errors. & $193(64.3)$ & $4.94 \pm 1.45$ \\
\hline \multirow[t]{3}{*}{$\begin{array}{l}\text { Error reporting } \\
\text { confidence }\end{array}$} & $\begin{array}{l}\text { I would feel comfortable reporting any errors I had made, no matter how } \\
\text { serious the outcome had been for the patient. }\end{array}$ & $178(59.3)$ & $4.73 \pm 1.36$ \\
\hline & $\begin{array}{l}\text { I would feel comfortable reporting any errors other people had made, no matter } \\
\text { how serious the outcome had been for the patient. }\end{array}$ & $153(51.0)$ & $4.56 \pm 1.34$ \\
\hline & $\begin{array}{l}\text { I am confident I could talk openly to my senior colleague about an error I } \\
\text { had made if it had resulted in potential or actual harm to my patient. }\end{array}$ & $203(67.7)$ & $4.92 \pm 1.45$ \\
\hline \multirow[t]{3}{*}{ Error inevitability } & Very experienced health professionals make errors. & $280(93.3)$ & $6.25 \pm 1.04$ \\
\hline & The clinical environment can cause errors. & $273(91.0)$ & $6.03 \pm 1.07$ \\
\hline & Human error is inevitable. & $274(91.3)$ & $6.21 \pm 1.09$ \\
\hline \multirow{3}{*}{$\begin{array}{l}\text { Professional } \\
\text { incompetence as } \\
\text { error cause }\end{array}$} & Most medical errors result from careless health professionals. $<R>$ & $101(33.7)$ & $3.83 \pm 1.44$ \\
\hline & If people paid more attention at work, medical errors would be avoided. $<R>$ & $189(63.0)$ & $4.75 \pm 1.42$ \\
\hline & Medical errors are a sign of incompetence. $<R>$ & $35(11.7)$ & $2.51 \pm 1.46$ \\
\hline
\end{tabular}




\begin{tabular}{|c|c|c|c|}
\hline Domain & Item & $\begin{array}{c}\text { No. of } \\
\text { agreements }(\%)\end{array}$ & $\begin{array}{l}\text { Mean } \pm \text { standard } \\
\text { deviation }\end{array}$ \\
\hline \multirow[t]{6}{*}{$\begin{array}{l}\text { Disclosure } \\
\text { responsibility }\end{array}$} & $\begin{array}{l}\text { It is not necessary to report errors which do not result in harm for the patient. } \\
<\mathrm{R}>\end{array}$ & $45(15.0)$ & $2.68 \pm 1.67$ \\
\hline & $\begin{array}{l}\text { Doctors have a responsibility to disclose errors to patients only if they result } \\
\text { in harm. }\end{array}$ & $247(82.3)$ & $5.61 \pm 1.32$ \\
\hline & All medical errors should be reported. & $207(69.0)$ & $5.08 \pm 1.47$ \\
\hline & $\begin{array}{l}\text { Junior members of a team should think carefully before speaking up about } \\
\text { patient safety. }<\mathrm{R}>\end{array}$ & $160(53.3)$ & $4.61 \pm 1.61$ \\
\hline & For optimum safety, cooperation and sharing of information is crucial. & $268(89.3)$ & $5.99 \pm 1.15$ \\
\hline & $\begin{array}{l}\text { The safest teams are those where different professional groups learn from } \\
\text { and with each other. }\end{array}$ & $269(89.7)$ & $5.91 \pm 1.16$ \\
\hline \multirow{3}{*}{$\begin{array}{l}\text { Patient's role in } \\
\text { error }\end{array}$} & Patients have an important role in preventing medical errors. & $222(74.0)$ & $5.35 \pm 1.37$ \\
\hline & $\begin{array}{l}\text { Actively seeking feedback from patients about quality and safety of care is } \\
\text { important for patient safety. }\end{array}$ & $250(83.3)$ & $5.65 \pm 1.20$ \\
\hline & Patients are not really aware of how safe their care is. $<R>$ & $219(73.0)$ & $5.10 \pm 1.23$ \\
\hline \multirow{3}{*}{$\begin{array}{l}\text { Importance of } \\
\text { patient safety in } \\
\text { the curriculum }\end{array}$} & $\begin{array}{l}\text { Teaching students about patient safety should be an important priority in training } \\
\text { undergraduates. }\end{array}$ & $232(77.3)$ & $5.33 \pm 1.27$ \\
\hline & $\begin{array}{l}\text { Patient safety issues cannot be taught and can only be learned through clinical } \\
\text { experience when qualified. }<R>\end{array}$ & $124(41.3)$ & $4.01 \pm 1.65$ \\
\hline & $\begin{array}{l}\text { Learning about patient safety issues before I qualify will enable me to become } \\
\text { a more effective health professional. }\end{array}$ & $94(31.3)$ & $3.36 \pm 1.94$ \\
\hline \multirow[t]{3}{*}{$\begin{array}{l}\text { Situational } \\
\text { awareness }\end{array}$} & $\begin{array}{l}\text { Being on the look-out for potential risks can be detrimental for patient safety. } \\
<R>\end{array}$ & $216(72.0)$ & $5.29 \pm 1.49$ \\
\hline & $\begin{array}{l}\text { Planning together to deal with problems that may arise is important for patient } \\
\text { safety. }\end{array}$ & 250 (83.3) & $5.71 \pm 1.19$ \\
\hline & $\begin{array}{l}\text { Understanding the roles and responsibilities of every member of the team } \\
\text { is important for patient safety. }\end{array}$ & 264 (88.0) & $5.99 \pm 1.13$ \\
\hline
\end{tabular}

Agreement: 5 (slightly agree) to 7 (strongly agree). ' $R$ ': score should be reversed.

through clinical experience after qualification, while only $31 \%$ indicated that it was effective to learn about patient safety issues before becoming qualified health professionals. More than half of all respondents indicated confidence about error reporting and the responsibility of disclosure while working in the capacity of a doctor. However, more than half agreed that junior team members should think carefully before initiating discussions about patient safety. Over $90 \%$ believed that human error was inevitable and that medical errors were not indicative of incompetence. Approximately one-third believed that most medical errors resulted from careless health professionals, while around two-thirds believed that medical errors could be avoided by paying more attention while at work. Regarding situational awareness, $72 \%$ believed that remaining vigilant about potential risks could actually be detrimental to patient safety (Table 2).

\section{Discussion}

This study investigated attitudes about patient safety among Korean medical students with at least 1 year of clinical clerkship. Because respondents thus had no formal patient safety training, their perceptions may have been affected by information received from informal and/or hidden curricula in the clinical environ- 
ment. Answers to several survey items seemed to require a change of perception related to patient safety among respondents.

More than one-third of this study's respondents believed that most harm to patients was unavoidable. This was less than the percentages found by previous studies. For instance, about $70 \%$ of medical-student respondents to studies based in both Hong Kong and Iran agreed that most such harm was unavoidable [7,8]. Regardless, a substantial number of this study's respondents require a change of perception.

The next item of note was error-reporting confidence. Although none of the respondents had received formal patient-safety instruction, more than half were confident in reporting errors regardless of who made them. This was similar to the findings of previous studies $[2,9,10]$. However, over half were also afraid of initiating discussions as junior members. Similarly, a study among American medical students reported that $92 \%$ intended to report all encountered patient-safety issues, but that about $70 \%$ felt uncomfortable expressing concerns about their own mistreatment to superiors [11]. These figures indicate that medical students are afraid of and reluctant to discuss mistakes with their superiors. This issue may be the result of hierarchies and/or the lack of errordisclosure training.

Most respondents were generous with their error inevitability estimates. Similarly, about $70 \%$ of respondents in previous studies agreed that even competent physicians make medical errors that lead to patient harm [7,8]. By contrast, they also seemed to believe that errors partially resulted from professional incompetence. That is, mean respondent scores were 3.83 out of 7 points for the item "Most medical errors result from careless health professionals." This was similar to the scores found in a study among medical students from Hong Kong and Singapore [10]. Furthermore, two-thirds of all re- spondents agreed with the item "If people paid more attention at work, medical errors would be avoided." This also indicates a misperception similar to that involving the tendency to blame careless medical professionals in the above item. Many medical students in Hong Kong and Singapore appear to agree with this opinion [10]. Furthermore, although only $11.7 \%$ of this study's respondents believed that medical errors indicated incompetence, many more medical students in previous research projects have indicated the same [10]. Based on the findings of both this and previous studies, there is still a tendency to blame medical errors on the individual (e.g., carelessness or paying less attention).

About two-thirds of all respondents believed that patient-safety issues could only be learned through clinical experience after qualification, which was also similar to the results of a previous study [10]. Further, only $31.3 \%$ believed that it was effective to learn about patient safety before qualification. This is a very low percentage when compared to those found by previous studies [7,9]. This may be because Korean undergraduate medical education does not tend to focus on patient safety. Respondents did not seem to believe they could learn much about patient safety before qualification.

In terms of situational awareness, $72 \%$ of all respondents believed that remaining vigilant about potential risks could actually be detrimental to patient safety. While there are no previous studies with which to compare this figure, the results indicate that increased attention should be paid to the potential risks; efforts should be made to improve student misunderstandings in this area.

This study had a few limitations. First, data were only gathered from among four institutions, thus preventing generalizability. Second, since all data were collected anonymously and only minimal personal information was retrieved, it was not possible to compare the APSQ 
between the institutions. As such, we were not able to determine APSQ differences concerning hidden curricula at any of the four institutions.

Even with its limitations, our findings revealed several important issues. For instance, it is clear that medical students should become more familiar with patient safety through their curricula. They should be aware that they can initiate discussions as a team member despite the established occupational hierarchy. Finally, students should learn to both identify and improve potential risks and human factors while contributing to overall patient safety. It is now essential for future doctors to receive patient safety training. Attitudes toward patient safety are highly important in this context due to their substantial impacts on behavioral decisions in the clinical setting. This study's results should serve as baseline data for use in developing patient-safety courses in the context of undergraduate medical education.

\section{ORCID:}

Kwi Hwa Park: https://orcid.org/0000-0002-0008-2400; Kyung Hye Park: https://orcid.org/0000-0002-5901-6088; Youngjoon Kang: https://orcid.org/0000-0002-3550-7755; Oh Young Kwon: https://orcid.org/0000-0003-0817-2256

Acknowledgements: None.

Funding: This research was supported by the National Research Foundation of Korea (NRF) grant funded by the Korea government (Ministry of Science, ICT \& Future Planning; No., 2017R1C1B5074565).

Conflicts of interest: No potential conflict of interest relevant to this article was reported.

Author contributions: Conception or design of the work: KHP2; data collection, data analysis and interpretation: KHP1, YK, OYK; drafting the article: KHP1; critical revision of the article: KHP2; and final approval of the version to be published: KHP1, KHP2.

\section{References}

1. Kohn LT, Corrigan J, Donaldson MS; Institute of Medicine; Committee on Quality of Health Care in America. To err is human: building a safer health system. Washington DC, USA: National Academy Press; 2000.

2. Lee HY, Hahm MI, Lee SG. Undergraduate medical students' perceptions and intentions regarding patient safety during clinical clerkship. BMC Med Educ. 2018; 18(1):66.

3. World Health Organization. WHO patient safety curriculum guide for medical schools. Geneva, Switzerland: World Health Organization; 2009.

4. Korean Association of Medical Colleges. Learning outcomes of basic medical education: human and societycentered. Seoul, Korea: Gabyumunhwasa; 2017.

5. Carruthers S, Lawton R, Sandars J, Howe A, Perry M. Attitudes to patient safety amongst medical students and tutors: developing a reliable and valid measure. Med Teach. 2009;31(8):e370-e376.

6. World Health Organization. Process of translation and adaptation of instruments. http://www.who.int/substance _abuse/research_tools/translation/en/. Accessed July 17, 2019.

7. Leung GK, Patil NG. Patient safety in the undergraduate curriculum: medical students' perception. Hong Kong Med J. 2010;16(2):101-105.

8. Nabilou B, Feizi A, Seyedin H. Patient safety in medical education: students' perceptions, knowledge and attitudes. PLoS One. 2015;10(8):e0135610.

9. Kiesewetter J, Kager M, Lux R, Zwissler B, Fischer MR, Dietz I. German undergraduate medical students' attitudes and needs regarding medical errors and patient safety: a national survey in Germany. Med Teach. 2014; 
36(6):505-510.

10. Leung GK, Ang SB, Lau TC, Neo HJ, Patil NG, Ti LK. Patient safety culture among medical students in Singapore and Hong Kong. Singapore Med J. 2013; 54(9):501-505.
11. Liao JM, Etchegaray JM, Williams ST, Berger DH, Bell SK, Thomas EJ. Assessing medical students' perceptions of patient safety: the medical student safety attitudes and professionalism survey. Acad Med. 2014;89(2):343-351. 